\title{
Epidemiology of Blastocystis infection from 1990 to 2019 in China
}

\author{
Chao-Qun Ning ${ }^{1,2}$, Zhu-hua Hü ${ }^{3}$, Jun-hu Chen ${ }^{1,2}$, Lin Ai ${ }^{1,2}$ and Li-Guang Tian ${ }^{1,2^{*}}$ (i)
}

\begin{abstract}
Background: Blastocystis is ubiquitous presence in animals and humans worldwide and has a high level genetic diversity. The aim of this study was to conduct a summary of Blastocystis prevalence, subtypes (STs) in humans and animals in China and depict their distribution.

Methods: We searched for the articles related to epidemiology of Blastocystis in humans and animals throughout China which published from January 1, 1990, to July 31, 2019 in the following databases: PubMed, China National Knowledge Infrastructure (CNKI) and Wanfang database. The keywords were Blastocystis and one of the following ones: STs, subtypes, distribution, epidemiology, prevalence, infection, molecular, geographic, intestinal parasites, genetic diversity and characterization.
\end{abstract}

Results: In recent years, various molecular epidemiological studies have been carried out in some provinces/ regions of China to identify subtypes of Blastocystis. Infants and young children, school students, hospitalized diarrhea patients, HIV/AIDS patients, tuberculosis patients, and cancer patients as respondents had been included. ST1-ST7 and ST12 were the main subtypes in Chinese population. Moreover, surveys of Blastocystis infection in animal were also conducted in some provinces of China. A variety of animals were investigated including pigs, cattle, sheep, yak, giant panda, and crested ibis (Nipponia nippon) with the main subtypes of ST1-ST8, ST10, ST12-ST14.

Conclusions: In recent years, some provinces/regions in China have conducted various molecular epidemiological studies to identify the Blastocystis subtypes. It is important to focus on new subtypes and mixed subtypes of infection, while increasing data on ribosomal alleles. We encourage the scientific community to start research on humans and surrounding animals (including domestic and wild animals) to better understand the possibility of Blastocystis transmission between humans and animals. We call for action among researchers studying intestinal parasitic diseases (Blastocystis), start drawing the subtype of Blastocystis and increase the subtype related to its clinical symptoms.

Keywords: Blastocystis, Epidemiology, Prevalence, Subtype, Diversity, China

\section{Background}

Blastocystis is widely distributed throughout the world. It is an anaerobic intestinal parasite that can infect humans and a variety of animals $[1,2]$. Blastocystis is the most common intestinal protozoa in human fecal specimens, which probably due to its rapid propagation and survival

\footnotetext{
*Correspondence: jztlg@126.com

${ }^{1}$ Chinese Center for Disease Control and Prevention, National Institute of Parasitic Diseases, Shanghai 200025, People's Republic of China Full list of author information is available at the end of the article
}

ability in different hosts such as humans and animals. Similar to the transmission route of some intestinal protozoans, the route of Blastocystis in humans and animals is via fecal-oral transmission, such as through contaminated water and food [3]. Based on gene analysis of small subunit of the ribosomal RNA (SSU-rRNA), wide genetic diversity is observed within Blastocystis, and multiple subtypes (STs) have been reported [4]. Currently, at least 17 subtypes are known, of which ST1 to ST8 and ST12 have been reported in humans [5, 6]; ST9 was exclusively identified in humans; and ST10-ST17 were identified original author(s) and the source, provide a link to the Creative Commons licence, and indicate if changes were made. The images or other third party material in this article are included in the article's Creative Commons licence, unless indicated otherwise in a credit line to the material. If material is not included in the article's Creative Commons licence and your intended use is not permitted by statutory regulation or exceeds the permitted use, you will need to obtain permission directly from the copyright holder. To view a copy of this licence, visit http://creativecommons.org/licenses/by/4.0/. The Creative Commons Public Domain Dedication waiver (http://creativeco mmons.org/publicdomain/zero/1.0/) applies to the data made available in this article, unless otherwise stated in a credit line to the data. 
only in animals [7]; novel subtypes are still being discovered [8]; and mixed-subtype infections of Blastocystis occurs [9]. ST1-ST4 commonly occur in humans, but ST4 is only reported in European region [10].

Clinical manifestations of Blastocystis are very diverse, including acute or chronic diarrhea, abdominal pain, nausea, anorexia, bloating, fatigue and flatulence $[11,12]$, along with allergy [13]. The prevalence of Blastocystis is high. Obviously, this parasite has a certain impact on human health, but its role in human health and disease is still uncertain [14]. A high rate of asymptomatic carriers exist in Blastocystis infections, and it is still uncertain whether the clinical symptoms of Blastocystis infection are related to a specific subtype or several subtypes of Blastocystis; or whether it is colonized by multiple parasites, causing the pathogenicity in Blastocystis under strong debate $[2,3]$. But, Clark proposed that different subtypes may have different pathological potentials [15]. Kaneda et al. suggested that ST1, ST2 and ST4 may be related to gastrointestinal symptoms [16]. Blastocystis ST1 is regarded as a pathogenic subtype and associated with irritable bowel syndrome diarrhoea (IBS-D) [17]. Blastocystis ST3 is considered to be virulent, which not only increases the pathogenicity of this parasite, but also increases the level of IgE in the serum, thereby causing allergies [13]. Jimenez et al. [3] proposed that the pathogenicity of Blastocystis is still controversial for many reasons, for example, the high proportion of asymptomatic carriers, host susceptibility, differences in intestinal microbiota and different pathogenic potentials of different Blastocystis subtypes. The prevalence of Blastocystis is high in some areas of China, which is mainly attributed to use of earthen toilets or manure pits, contact with animal, drinking unboiled water directly and poor hygiene [18, 19]. Blastocystis can colonize the intestines of humans, domestic animals (cattle, sheep, goats and pigs) and wild animals, which has been observed in many provinces in China. Therefore, we describe herein our summary of the studies about epidemiology of Blastocystis in humans and animals throughout China, and aim to depict the prevalence of Blastocystis in different provinces, display the distribution of Blastocystis subtypes among different hosts (humans and animals).

\section{Methods}

\section{Search strategy}

Geographically, the study domain was restricted to research in China. Studies reported in English and Chinese were selected. The information in the article includes whether Blastocystis and epidemiology (infection status and/or subtype) in humans or animals are mentioned.
Both PubMed and China National Knowledge Infrastructure (https://www.cnki.net/) and Wanfang (http:// www.wanfangdata.com.cn/index.html) database were used to find potentially eligible articles. The articles about epidemiology of Blastocystis were searched in humans and animals throughout China, which were published from January 1, 2010, to July 31, 2019. There included keywords Blastocystis and one of the following keywords: STs, subtypes, distribution, epidemiology, prevalence, infection, molecular, geographic, intestinal parasites, genetic diversity and characterization. Duplicate studies from the three databases were removed. We excluded conference abstract papers, case reports, case series and review articles. For the same survey, multiple results may be published in different forms, and we select articles with complete results. A total of 215 articles were found, and only 82 of them met the above criteria (Fig. 1). More details of the 82 articles were displayed in Additional file 1: Table S1, including title, author, journal.

\section{Information extraction and analysis}

Two investigators independently screened abstracts, full-text articles, performed data extraction. Data were extracted by the first investigator from the included articles, evaluated by the second investigator and final evaluation was conducted by the third investigator. The characteristics were extracted from each study, including the surveyed province, number of samples, number of samples positive for Blastocystis, host, detection method, subtypes, number of samples per subtype, article title, first author and year of publication. We extracted relevant information from each article that met the inclusion criteria of this study.

According to the different detection methods of Blastocystis in the study, the overall infection rate in China and the infection rate in each province were calculated, and revealed the distribution of subtypes in different provinces in China. At the same time, we could determine the distribution of subtypes in humans and different kinds of animals.

\section{Results}

\section{Distribution of investigation of Blastocystis infection}

For the study of Blastocystis infection in humans, we divide the humans into the general population, students, children, hospitalized or outpatients, diarrhea cases, and people with HIV or tuberculosis and other diseases. We have summarized the infection of Blastocystis in humans and animals, shown in Tables 1 and 2.

\section{Risk factors of Blastocystis infection in humans}

The risk factors of Blastocystis infection are diverse. Several studies have shown that not washing hands after 


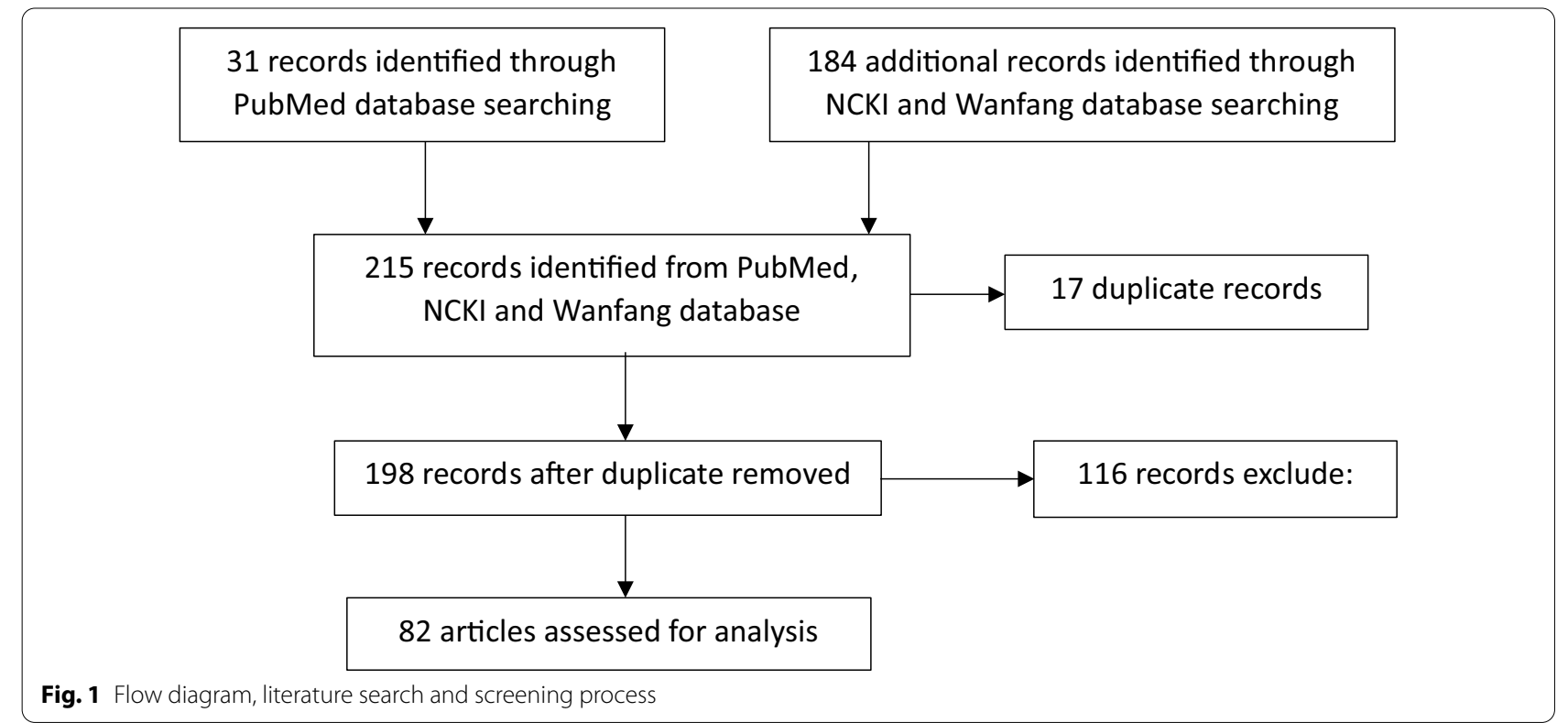

going to the toilet, drinking unboiled tap water, eating outside for a long time, raising poultry or livestock, low immune function, poor nutritional status, female, body mass index $<19$, anemia and barefoot working in farm are the risk factors that cause Blastocystis infection [21, 28, $29,32,44,45]$. In addition, suffering from some underlying diseases such as Helicobacter pylori infection and hepatitis B are also risk factors for Blastocystis infection [46].

\section{Infection status and subtypes of Blastocystis in general population}

In general population, the infection status and subtype distribution of Blastocystis in China are shown in Table 1. The infection rate of Blastocystis in the population has regional differences. For example, surveys in different regions of Guangxi found that the infection rate of Blastocystis in Bama Yao Autonomous County was 43.26\%, and in Beihai and Qinzhou was 36.35\% [24, 25]. The methods used in the two studies were the same and the subjects were the local general population. Yan et al. identified that the subtypes of Blastocystis in humans were ST1-ST3. ST3 was the main subtype $(40.0 \%)$, followed by ST1 (37.1\%), the mixed subtype of ST1 and ST3 accounted for $14.3 \%$, and unknown subtypes have also been found [47].

\section{Blastocystis infection in students and children}

There are few studies focus on Blastocystis infection in students. The infection rate of Blastocystis in primary and university students from Jiangxi was $1.10 \%$ and $10.09 \%$, respectively [48, 49]. The prevalence of Blastocystis in college students in Guangxi was 14.93\% [50]. Another study in Guangxi found that infection subtypes include ST1, ST3, ST4, ST6 and ST7, among which ST3 was the main subtype (32.08\%) [51].

A study found that children in Jiangxi Province have a higher infection rate (35.9\%) and have symptoms such as diarrhea and recurrent abdominal pain [52]. The infection rate of children with diarrhea in Yunnan (3.1\%) and Fujian (8.94\%) was lower than that in Jiangxi $[53,54]$. Cao et al. performed fecal microscopy on children in Shenzhen Children's Hospital and found that the infection rate of Blastocystis was low (0.4\%) [55].

\section{Infection status and subtype of Blastocystis in inpatients or outpatient without distinction of disease}

Some investigations related to Blastocystis infections were conducted in the hospitals, and the subjects were hospitalized or outpatients. These patients were randomly selected from the hospital. The infection rate of patients in the First Affiliated Hospital of Guangxi Medical University was $22.78 \%$, and the infection rate was significant different in gender. The disease of these patients was not clear [56]. The study found that the infection rate of Blastocystis in hospitals in Nanning, Guangxi has little change over time. The prevalence of patients were $16.27 \%$ and $16.77 \%$, respectively in 2005 and 2013 [57].

\section{Blastocystis infection and its subtypes in patients with diarrhea}

Blastocystis was one of the common pathogens in patients with diarrhea. The main manifestations of patients with Blastocystis include abdominal pain or diarrhea, followed 


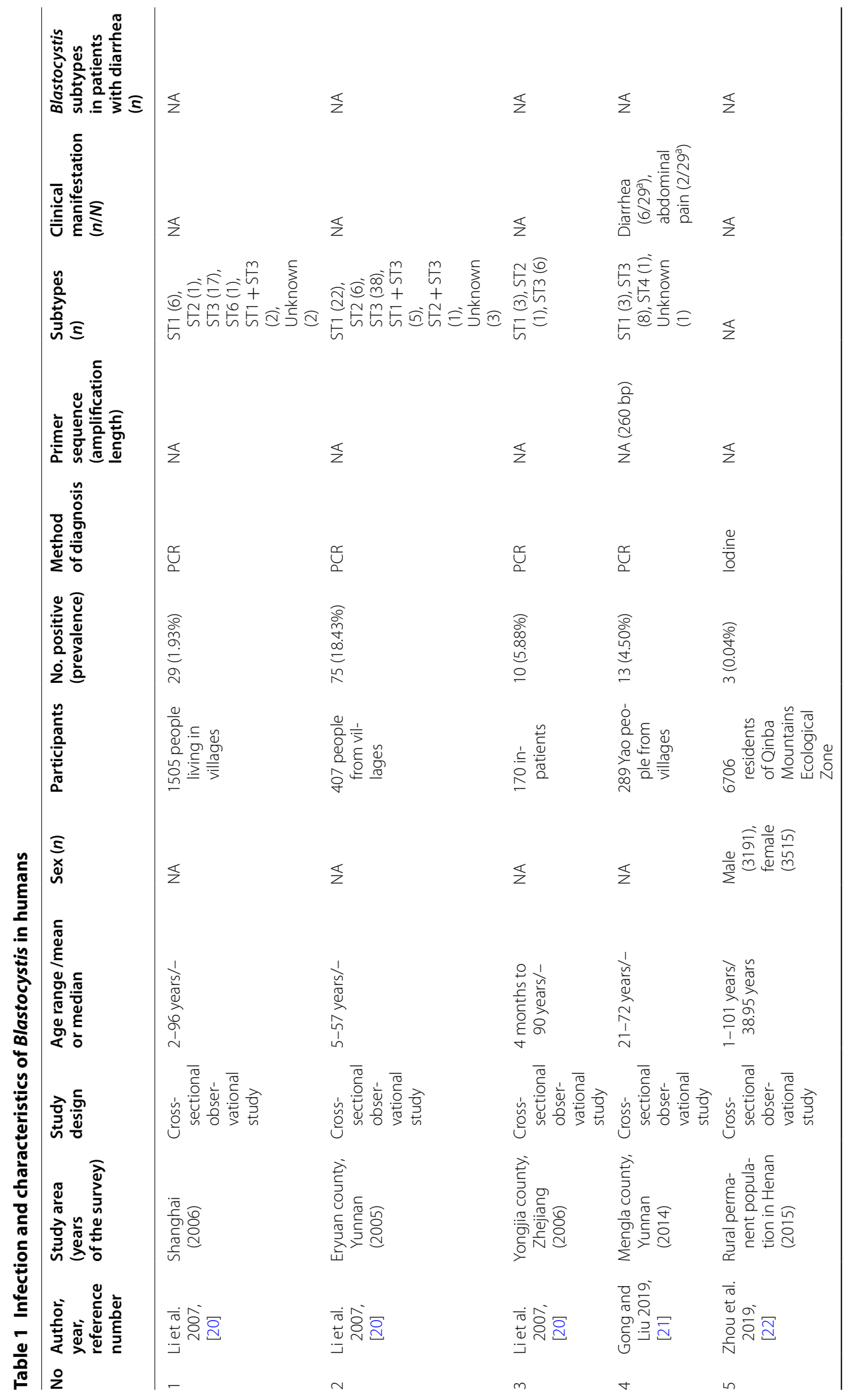




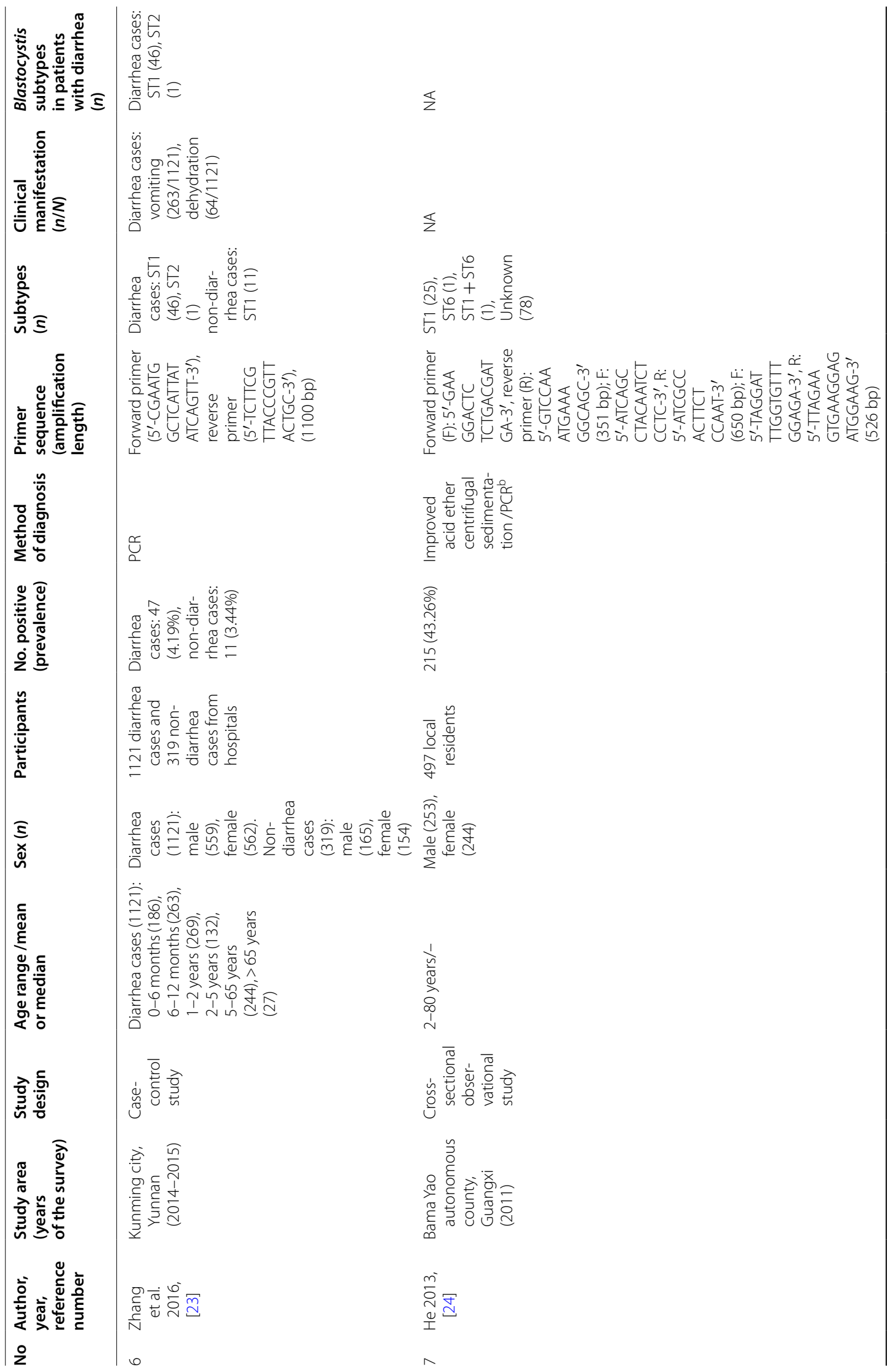




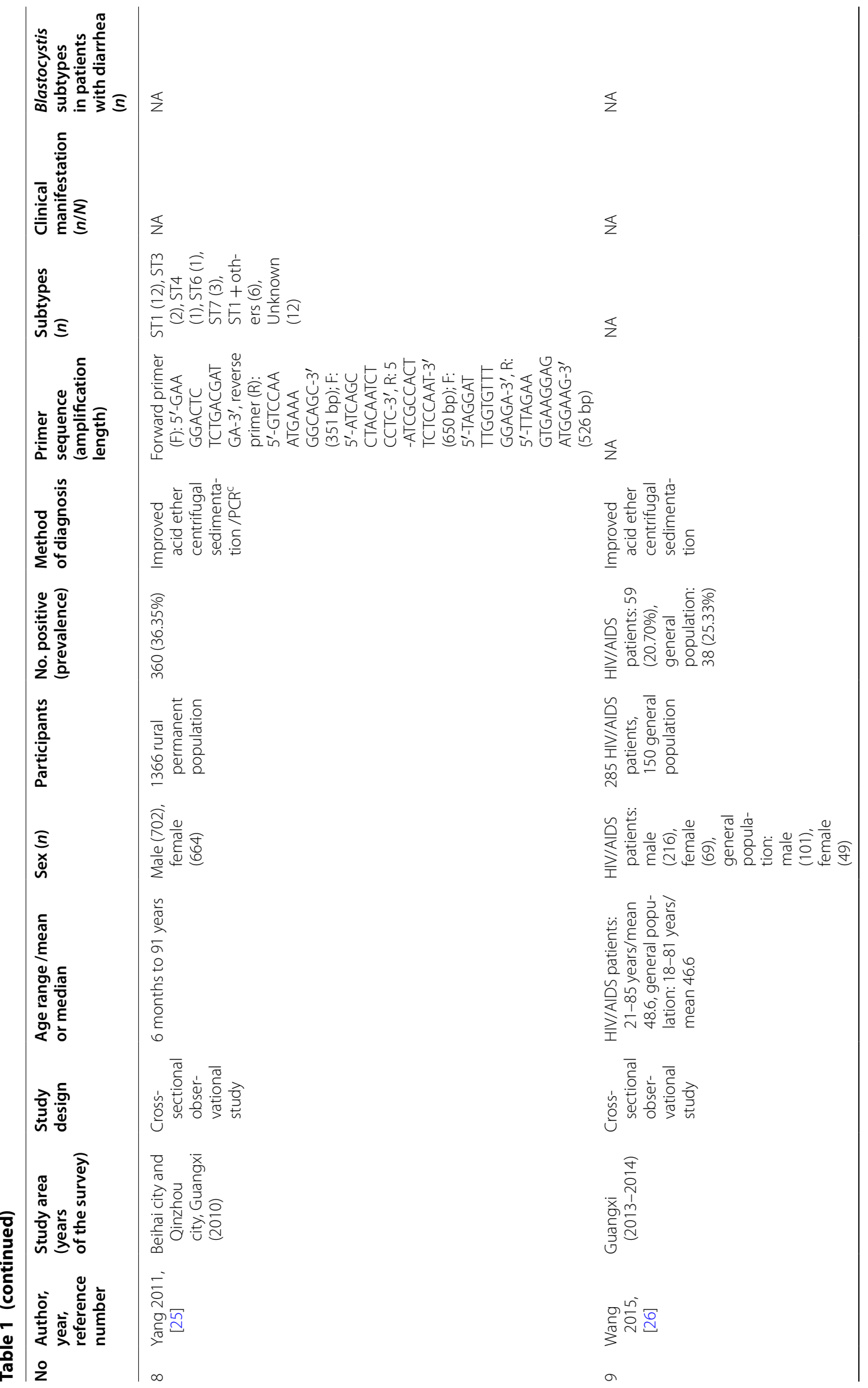




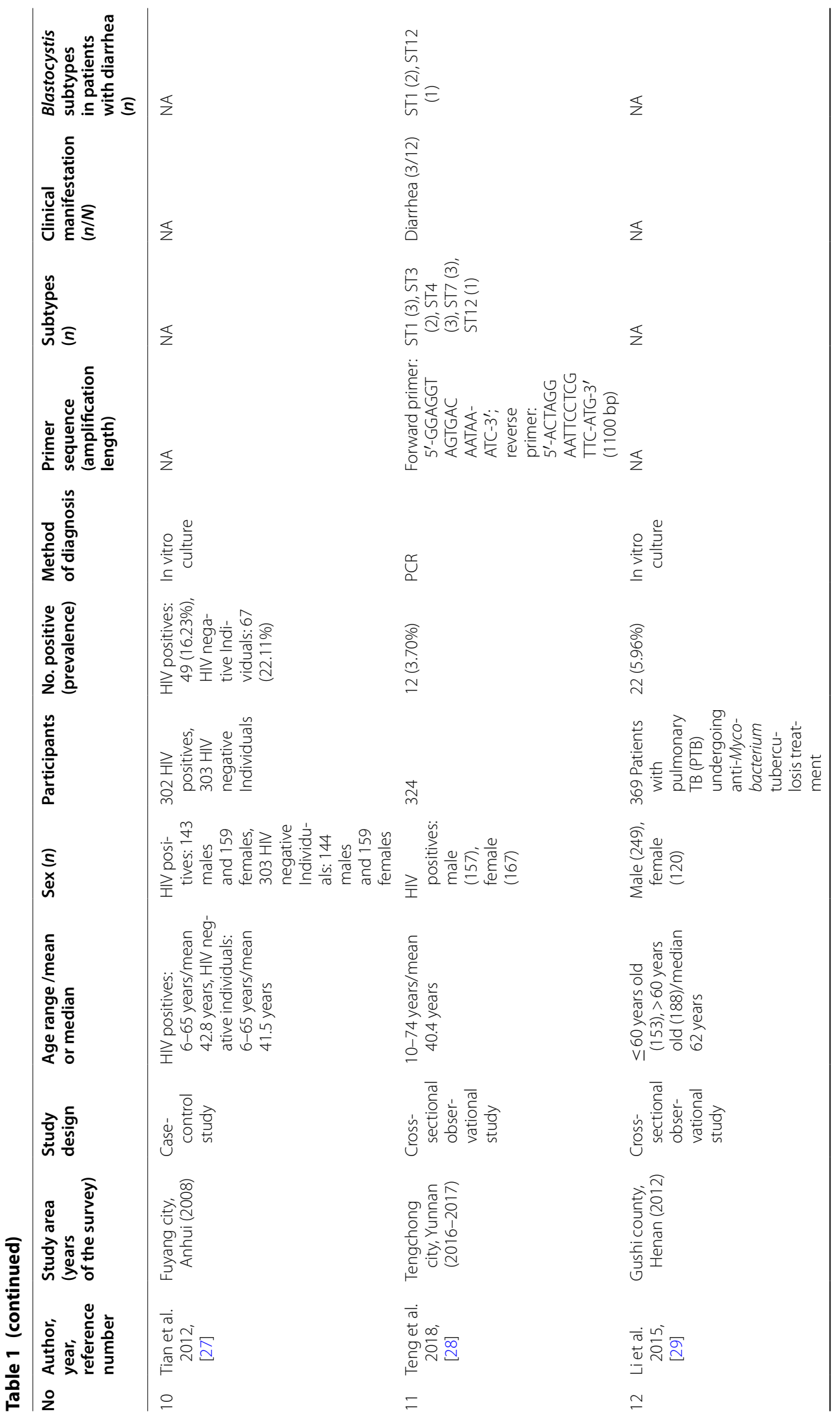




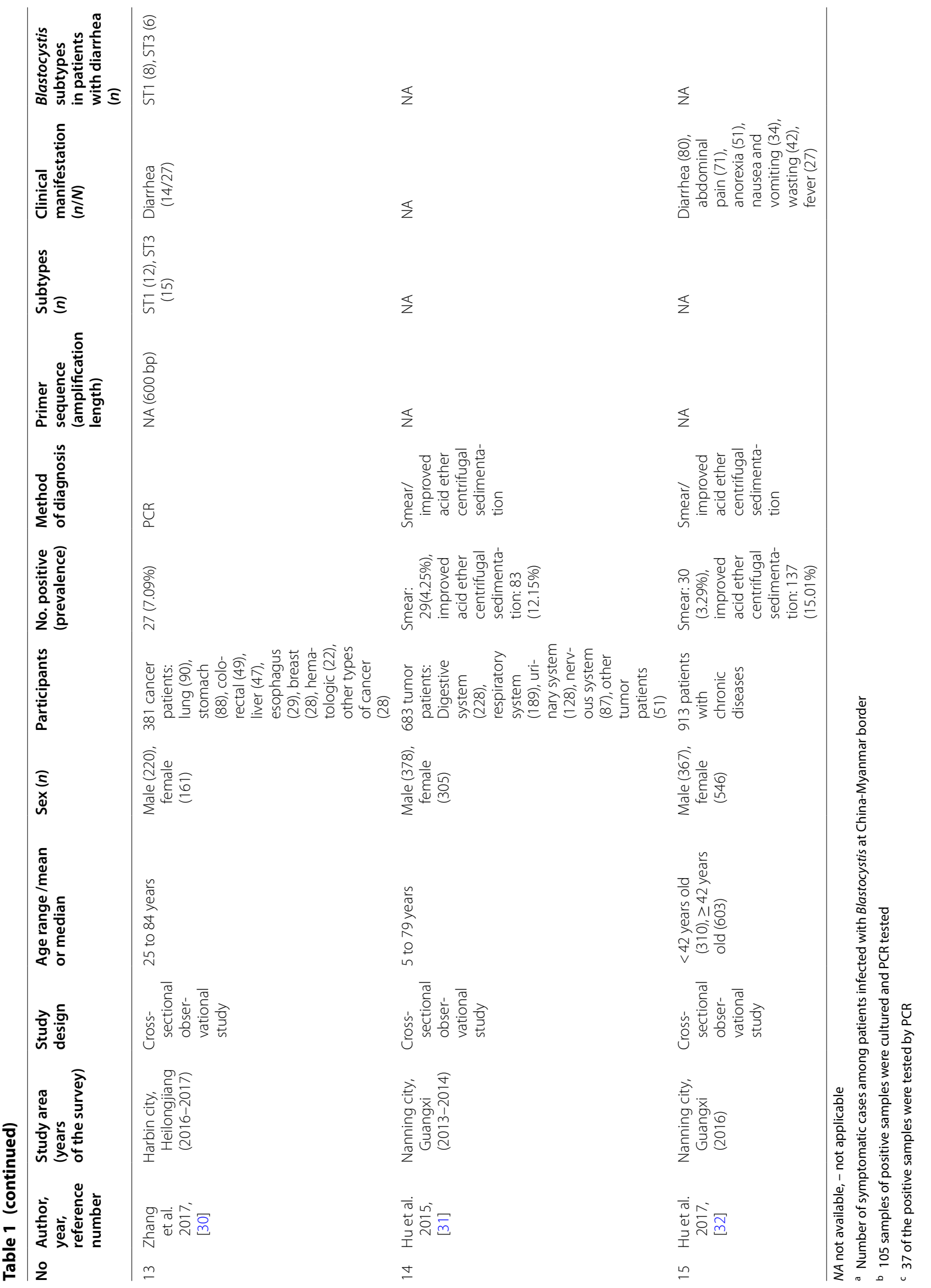


by fatigue and anorexia. Some researchers have found that these gastrointestinal symptoms may be related to colitis [58]. Diarrhea patients have different infection rates in different seasons, and the subtype was mainly ST1 [23, 59]. There are few studies on the association between the subtypes of Blastocystis and clinical manifestations, some of which are related to the subtypes of Blastocystis in patients with diarrhea (Table 1).

\section{Blastocystis infection in patients with underlying diseases}

There are few studies on the co-infection of Blastocystis and underlying diseases (HIV/AIDS patients, tuberculosis patients, cancer patients and chronic disease patients). The prevalence, clinical manifestation and subtypes of Blastocystis in patients with HIV/AIDS, pulmonary $\mathrm{TB}$, cancer and chronic diseases show in Table 1. Blastocystis and HIV co-infection were studied in Yunnan, Anhui and Guangxi provinces. Studies have suggested that Blastocystis infection increases the level of IL-2 in HIV-infected persons, changes the Th1/Th2 balance, and accelerates the conversion of HIV infection to AIDS [60]. In China, ST12 infection was first detected in AIDS patients in 2018 [28]. There was no difference in the infection of Blastocystis in tuberculosis patients (6.2\%) and the healthy group (7.6\%) [44]. The detection of cancer patients found that the infection rate of Blastocystis in lung, stomach, colorectal cancer patients was higher than that of other cancer patients, and the infection rate of cancer patients was significantly higher than that of the general population (malignant tumors: $43.24 \%$, nonmalignant tumors: $22.59 \%, 19.70 \%$ of the general population) [61]. The symptoms of diarrhea in cancer patients may be related to ST1 [30]. The infection rate of Blastocystis in patients with chronic disease was $18.29 \%$, and clinical symptoms such as abdominal pain, diarrhea, and vomiting may occur [32].

\section{Distribution and infection of Blastocystis in animals}

There is a list of the distribution and genetic diversity of Blastocystis in different animals including non-human primates, birds, and mammals in China. Some provinces have performed genotyping of animal Blastocystis (Table 2). There are significant differences in the prevalence of Blastocystis in pigs in different regions and age groups [34]. The infection rate of Blastocystis in cats was low. Among the 346 cats surveyed in six provinces, only 2 cats were found to be infected with Blastocystis in Lu'an, Anhui Province [42]. Among animal Blastocystis isolates, the potential zoonotic subtype including ST1, ST3 and ST5 accounts for 38.5\% [38]. At the same time, insects could also be infected, and the body surface and digestive tract of cockroach and housefly can be infected with Blastocystis [62].

\section{Discussion}

Based on the above information, we found that the infection of Blastocystis in different populations and regions is different. The infection rate of primary school students was lower than that of college students [48, 49]. It may be that under the management of parents and teachers, primary school students have developed good hygiene habits, such as washing hands frequently. The investigations of Blastocystis infection in hospitalized patients found that the infection rate in Guangxi was higher than that in other regions. This may be due to the help of doctors after local residents developed symptoms such as diarrhea, or different detection methods used in the study. The specific reasons need to be studied in depth [63]. Studies on patients with diarrhea have shown that ST1 is related to clinical symptoms such as diarrhea and has potential pathogenicity. The main subtype of diarrhea patients is ST1, and the main subtype of asymptomatic Blastocystis infection is ST3 [23, 30, 45]. CD4+ cell count $\leq 500$ cells $/ \mu$ l, and an HIV-RNA viral load $>50$ copies/ml were the influencing factors of Blastocystis infection in HIV-seropositive individuals [64].

Considering the subtype of Blastocystis in humans and animals, this study found that ST1-ST7 and ST12 were present in the sample of humans in China [28, 63, 65], of which a large number were typed most frequently as ST1, ST2 and ST3 [21, 23, 51, 66], including mixed subtypes of ST1 and ST3, ST1 and ST2, and ST2 and ST3 [20], followed by other subtypes in minor percentages. Foreign studies have found that ST1-ST9 of Blastocystis can infect humans [67]. However, it has not been found that ST8 and ST9 can infect humans in China. This study found that ST1-ST8 and ST10, as well as ST12-ST14 were present in the sample of animals in China (Table 2). Some foreign studies have found that ST1-ST17 can infect animals [67]. However, ST9, ST11, ST15-ST17 have not been found to infect animals in China. In China, ST10 predominates in animal infection [39-41, 68, 69], followed by ST5 [34]. This is different from some foreign studies. An Italian study found that the subtype of Blastocystis infection in dogs was ST3 [70]. The subtype of Blastocystis infection in animals from the United States was mainly ST8 (20.6\%), followed by ST6 (17.3\%) and ST5 (15.9\%) [3]. Because ST1-ST8 subtypes can infect both humans and animals, there are studies abroad to explore the possibility of the transmission of Blastocystis between humans and animals. In 2019, a report in Lebanon believed that Blastocystis has a potential risk of transmission from livestock to its contacts. The study found that ST1, ST2, ST3 infected in cows and people who have been in contact with cows, and the sequence of ST3 is exactly the same between cows and their contacts [71]. Few studies conducted in this research field 


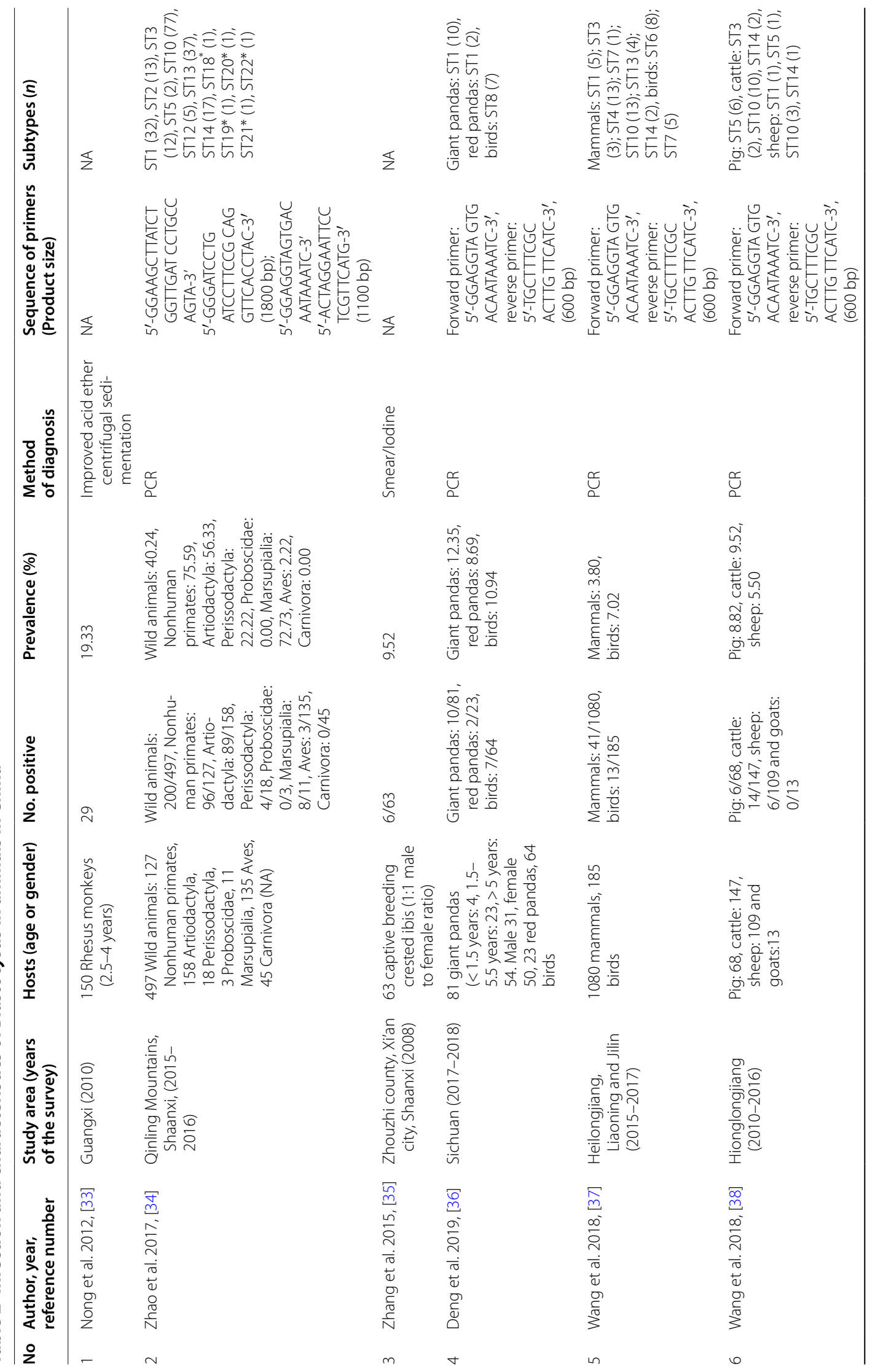




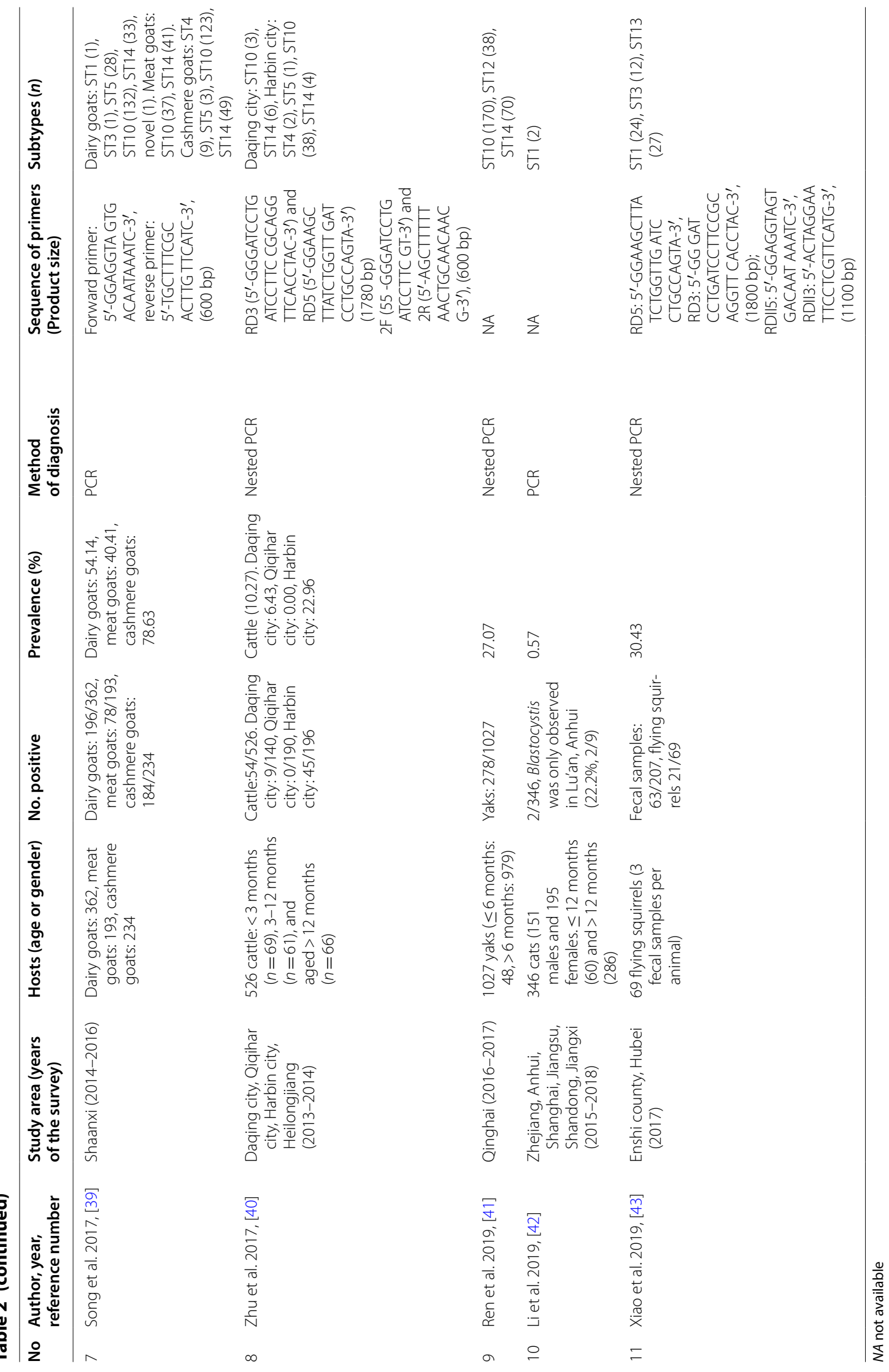


in China, and there is a lack of corresponding data. The most recent epidemiological data of Blastocystis and its subtypes are limited to reports from a few provinces in China $[40,53,59]$, and most of these reports come from research conducted by certain institutions. We are considering summarizing the distribution of Blastocystis and its subtypes in various provinces in China. However, there are no data available in many provinces/ regions. The fact that most of the research comes from a few provinces may be related to the fact that there are more investigators and enough attention. This shows that in underrepresented provinces, more investigators and more attention are needed to infer the true distribution of Blastocystis in different regions of China.

There are several limitations in our study. Firstly, most of our included studies were cross-sectional studies where selection bias may have occurred, for example, many research subjects are selected from hospitals, schools, etc. Secondly, the detection methods of Blastocystis in each study are different, and the primers and primer lengths are different when performing polymerase chain reaction (PCR) detection. Thirdly, some provinces have conducted fewer studies or only conducted studies in a certain urban area, and the majority of province no research on Blastocystis has been conducted, so some data are less representative. Finally, in addition to real differences, the possible reasons for the different infection rates among different regions may be attributed to the large time span of this study (19902019) and the possible differences in the results of the researcher's identification through microscopy.

\section{Conclusions}

In recent years, various molecular epidemiological studies have been conducted in some provinces/ regions of China to identify the subtypes of Blastocystis. We believe that it is important to focus on new subtypes and mixed subtypes of infection, while increasing data on ribosomal alleles. In addition, the relationship between Blastocystis subtypes and clinical symptoms should be studied. Finally, we should pay attention to the people and surrounding animals (including domestic and wild animals) to better explore the possibility and means of transmission of Blastocystis between humans and animals.

\section{Supplementary information}

Supplementary information accompanies this paper at https://doi. org/10.1186/s40249-020-00779-z.

Additional file 1: Articles that meet the criteria.
Abbreviations

ST: Subtype; CNKI: China National Knowledge Infrastructure; HIV: Human immunodeficiency virus; SSU-rRNA: Small Subunit Ribosomal RNA; IBS-D: Irritable bowel syndrome diarrhoea; PCR: Polymerase chain reaction.

\section{Acknowledgements}

We sincerely thank all the experts who have insights into this paper.

\section{Authors' contributions}

C-QN and L A performed the statistical analysis and drafted the paper. C-QN and L-GT conceived and designed the study. L A and L-GT critically reviewed the paper. $\mathrm{H}-\mathrm{ZH}$ and $\mathrm{C}-\mathrm{JH}$ modification to the paper. All authors read and approved the final manuscript.

\section{Funding}

This research was funded by the National Natural Science Foundation of China (81473022) and the Project of Shanghai Science and Technology Commission (18490741100).

\section{Availability of data and materials}

All datasets are presented in the main paper.

Ethics approval and consent to participate

Not applicable.

Consent for publication

Not applicable.

\section{Competing interests}

The authors declare that they have no competing interests.

\section{Author details}

${ }^{1}$ Chinese Center for Disease Control and Prevention, National Institute of Parasitic Diseases, Shanghai 200025, People's Republic of China. ${ }^{2}$ Key Laboratory for Parasitology and Vector Biology, $\mathrm{MOH}$ of China, WHO Collaborating Center for Tropical Diseases, National Center for International Research On Tropical Diseases, Shanghai 20025, People's Republic of China. ${ }^{3}$ Nanchang Center for Disease Control and Prevention, Nanchang 330038, People's Republic of China.

Received: 6 May 2020 Accepted: 11 November 2020

Published online: 30 December 2020

\section{References}

1. Tan KS. Blastocystis in humans and animals new insights using modern methodologies. Vet Parasitol. 2004;126:121-44.

2. Tan KS. New insights on classification, identification, and clinical relevance of Blastocystis spp. Clin Microbiol Rev. 2008;21:639-65.

3. Jimenez PA, Jaimes JE, Ramirez JD. A summary of Blastocystis subtypes in North and South America. Parasit Vectors. 2019;12:376.

4. Stensvold CR, Traub RJ, von Samson-Himmelstjerna G, Jespersgaard C, Nielsen HV, Thompson RC. Blastocystis: subtyping isolates using pyrosequencing technology. Exp Parasitol. 2007;116:111-9.

5. Stensvold CR, Clark CG. Current status of Blastocystis: A personal view. Parasitol Int. 2016;65:763-71.

6. Ramirez JD, Sanchez A, Hernandez C, Florez C, Bernal MC, Giraldo JC, et al. Geographic distribution of human Blastocystis subtypes in South America. Infect Genet Evol. 2016;41:32-5.

7. Alfellani MA, Taner-Mulla D, Jacob AS, Imeede CA, Yoshikawa H, Stensvold $C R$, et al. Genetic diversity of Blastocystis in livestock and zoo animals. Protist. 2013;164:497-509.

8. Parkar U, Traub RJ, Vitali S, Elliot A, Levecke B, Robertson I, et al. Molecular characterization of Blastocystis isolates from zoo animals and their animalkeepers. Vet Parasitol. 2010;169:8-17.

9. Skotarczak B. Genetic diversity and pathogenicity of Blastocystis. Ann Agric Environ Med. 2018;25:411-6.

10. Stensvold CR, Christiansen DB, Olsen KE, Nielsen HV. Blastocystis sp. subtype 4 is common in Danish Blastocystis-positive patients presenting with acute diarrhea. Am J Trop Med Hyg. 2011;84:883-5. 
11. Sohail MR, Fischer PR. Blastocystis hominis and travelers. Travel Med Infect Dis. 2005;3:33-8.

12. Zhang SX, Zhou YM, Xu W, Tian LG, Chen JX, Chen SH, et al. Impact of co-infections with enteric pathogens on children suffering from acute diarrhea in southwest China. Infect Dis Poverty. 2016a;27:64.

13. El Saftawy EA, Amin NM, Hamed DH, Elkazazz A, Adel S. The hidden impact of different Blastocystis genotypes on C-3 and lgE serum levels: a matter of debate in asthmatic Egyptian children. J Parasit Dis. 2019:43:443-51.

14. Andersen LO, Stensvold CR. Blastocystis in health and disease: Are we moving from a clinical to a public health perspective? J Clin Microbiol. 2016;54:524-8.

15. Clark CG. Extensive genetic diversity in Blastocystis hominis. Mol Biochem Parasitol. 1997:87:79-83.

16. Kaneda Y, Horiki N, Cheng $X$, Tachibana H, Tsutsumi Y. Serologic response to Blastocystis hominis infection in asymptomatic individuals. Tokai J Exp Clin Med. 2000;25:51-6.

17. Kesuma Y, Firmansyah A, Bardosono S, Sari IP, Kurniawan A. Blastocystis ST-1 is associated with irritable bowel syndrome-diarrhoea (IBS-D) in Indonesian adolescences. Parasite Epidemiol Control. 2019;6:e00112.

18. Zhang SX, Kang FY, Chen JX, Tian LG, Geng LL. Risk factors for Blastocystis infection in HIV/AIDS patients with highly active antiretroviral therapy in Southwest China. Infect Dis Poverty. 2019;8:89

19. Wang W, Owen H, Traub RJ, Cuttell L, Inpankaew T, Bielefeldt-Ohmann H. Molecular epidemiology of Blastocystis in pigs and their in-contact humans in Southeast Queensland, Australia, and Cambodia. Vet Parasitol. 2014:203:264-9.

20. Li LH, Zhang XP, Lv S, Zhang L, Yoshikawa H, Wu Z, et al. Cross-sectional surveys and subtype classification of human Blastocystis isolates from four epidemiological settings in China. Parasitol Res. 2007;102:83-90.

21. Gong B, Liu X, Wu Y, Xu N, Xu M, Yang F, et al. Prevalence and subtype distribution of Blastocystis in ethnic minority groups on both sides of the China-Myanmar border, and assessment of risk factors. Parasite. 2019;26:46.

22. Zhou RM, Li SH, Zhang YL, Deng Y, Chen WQ, Yang CY, et al. Investigation on human intestinal parasitic diseases in ecological regions of Qinba Mountains in Henan Province in 2015. Zhongguo Xue Xi Chong Bing Fang Zhi Za Zhi. 2019:31:148-54 (In Chinese).

23. Zhang SX, Tian LG, Lu Y, Li LH, Chen JX, Zhou XN. Epidemiological characteristics of Blastocystis hominis in urban region, southwestern China. Zhongguo Ren Shou Gong Huan Bing Za Zhi. 2016;32:424-8 (In Chinese).

24. He SS. Investigation on the infection of Blastocystis hominis various populations in Bama Yao Autonomous County of Guangxi and RAPD analysis of 105 isolates. Master: Guangxi Medical University; 2013. (In Chinese).

25. Yang Y. Investigation on human infection and obeserving on genetic variability of Blastocystis hominis in the south coastal areas of Guangxi province. Master: Guangxi Medical University; 2011. (In Chinese),

26. Wang ZF. Co-infection with HIV and Cryptosporidium or Blastocystis hominis in Guangxi and the genotype of Cryptosporidium. Master: Guangxi Medical University; 2015. (In Chinese).

27. Tian LG, Chen JX, Wang TP, Cheng GJ, Steinmann P, Wang FF, et al. Coinfection of HIV and intestinal parasites in rural area of China. Parasit Vectors. 2012;5:36

28. Teng XJ, Chu YH, Zhai CC, Yu YF, Cai YC, Chen SH, et al. The epidemiological characteristics and influencing factors for Blastocystis hominis infection among human immunodeficiency virus seropositive individuals in Tengchong of Yunnan Province. Zhongguo Ji Sheng Chong Xue Yu Ji Sheng Chong Bing Za Zhi. 2018;36:129-34 (In Chinese).

29. Li XX, Chen JX, Wang LX, Tian LG, Zhang YP, Dong SP, et al. Prevalence and risk factors of intestinal protozoan and helminth infections among pulmonary tuberculosis patients without HIV infection in a rural county in P. R China Acta Trop. 2015;149:19-26.

30. Zhang W, Ren G, Zhao W, Yang Z, Shen Y, Sun Y, et al. Genotyping of Enterocytozoon bieneusi and subtyping of Blastocystis in cancer patients. Relationship to diarrhea and assessment of zoonotic transmission. Front Microbiol. 2017;8:1825.

31. Hu Y, Song XQ, Li YW, Shi HH. Research on the infection status of Blastocystis hominis in patients with malignant tumour. Zhongguo Wei Sheng Jian Yan Za Zhi. 2015;25:1962-4 (In Chinese).
32. Hu Y, Li YW, Liu XQ, Shi JY. Investigation of infection in patients with chronic diseases. Zhongguo Wei Sheng Jian Yan Za Zhi. 2017;27:255860 (In Chinese).

33. Nong ZJ, Li YP, Mo G, Jiang LP, Li XD. Investigation of rhesus monkey infection with Blastocystis hominis in Guilin. Heilongjiang Xu Mu Shou Yi. 2012;2:105-6 (In Chinese)

34. Song JK, Hu RS, Fan XC, Wang SS, Zhang HJ, Zhao GH. Molecular characterization of Blastocystis from pigs in Shaanxi province of China. Acta Trop. 2017:173:130-5.

35. Zhang X, Qiao JY, Wu XM, Ma QY, Hu H, Wang J, et al. Ascaris spp and Capillaria caudinflata infections in captive-bred crested ibis (Nipponia nippon) in China. Zoo Biol. 2015;34:80-4.

36. Deng L, Yao JX, Liu HF, Zhou ZY, Chai YJ, Wang WY, et al. First report of Blastocystis in giant pandas, red pandas, and various bird species in Sichuan province, southwestern China. Int J Parasitol Parasites Wildl. 2019;9:298-304.

37. Wang J, Gong B, Liu X, Zhao W, Bu T, Zhang W, et al. Distribution and genetic diversity of Blastocystis subtypes in various mammal and bird species in northeastern China. Parasit Vectors. 2018;11:522.

38. Wang J, Gong B, Yang F, Zhang W, Zheng Y, Liu A. Subtype distribution and genetic characterizations of Blastocystis in pigs, cattle, sheep and goats in northeastern China's Heilongjiang Province. Infect Genet Evol. 2018;57:171-6.

39. Song JK, Yin YL, Yuan YJ, Tang H, Ren GJ, Zhang HJ, et al. First genotyping of Blastocystis sp in dairy, meat, and cashmere goats in northwestern China. Acta Trop. 2017;176:277-82.

40. Zhu W, Tao W, Gong B, Yang H, Li Y, Song M, et al. First report of Blastocystis infections in cattle in China. Vet Parasitol. 2017;246:38-42.

41. Ren M, Song JK, Yang F, Zou M, Wang PX, Wang D, et al. First genotyping of Blastocystis in yaks from Qinghai Province, northwestern China. Parasit Vectors. 2019:12:171.

42. Li W, Liu X, Gu Y, Liu J, Luo J. Prevalence of Cryptosporidium, Giardia, Blastocystis, and trichomonads in domestic cats in East China. J Vet Med Sci. 2019;81:890-6.

43. Xiao X, Zhou SH, Jiang N, Tian DZ, Zhou ZM, Zhang M, et al. First record of Leptospira and Blastocystis infections in captive flying squirrels (Trogopterus xanthipes) from Enshi County. China Acta Trop. 2019:197:105065

44. Li XX, Chen JX, Wang LX, Tian LG, Zhang YP, Dong SP, et al. Intestinal parasite co-infection among pulmonary tuberculosis cases without human immunodeficiency virus infection in a rural county in China. Am J Trop Med Hyg. 2014:90:106-13.

45. Jin QX, Yu KM, Tang LF, Tian CL, Lu ZC. Investigation of infectious status of Blastocystis hominis in 1354 outpatients. Zhongguo Re Dai Yi Xue. 2005:5:1469-71 (In Chinese).

46. Chen TL, Chan CC, Chen HP, Fung CP, Lin CP, Chan WL, et al. Clinical characteristics and endoscopic findings associated with Blastocystis hominis in healthy adults. Am J Trop Med Hyg. 2003;69:213-6.

47. Yan Y, Su S, Lai R, Liao H, Ye J, Li X, et al. Genetic variability of Blastocystis hominis isolates in China. Parasitol Res. 2006;99:597-601.

48. Cao HL, Wu GH, Guo ZZ. Infection of Blastocystis hominis among pupils in Nantang Town, Gan County. Gannan Yi Ke Da Xue Xue Bao. 1999:19:364 (In Chinese).

49. Su SL, Chen GF, Teng MC, Zhang RQ, Zhong RC, Liao H, et al. Investigation and analysis on the infection of intestinal parasites in grade 2002. Gannan Yi Ke Da Xue Xue Bao. 2002;22:540-1 (In Chinese).

50. Liu T, Liu XQ, Shi HH, He SS, Wang G, Fu RJ, et al. Investigation of college student infection with Blastocystis hominis in Guangxi Medical University. J Guangxi Med Univ. 2011;28:961-3 (In Chinese).

51. Zhan TZ, Liu T, Shi HH, He SS, Yan H, Liu DY. PCR-based genotype classification of Blastocystis hominis isolates from college students of Guangxi. Chin J Parasitol Parasit Dis. 2014;32:209-11 (In Chinese).

52. Zhao L, Dai SM, Chen FG. Study on chronic diarrhea and infection of Blastocystis in children in Jiangxi. Med Infor. 2015:28:62-3 (In Chinese).

53. Zhang SX, Zhou YM, Xu W, Tian LG, Chen JX, Chen SH, et al. Impact of co-infections with enteric pathogens on children suffering from acute diarrhea in southwest China. Infect Dis Poverty. 2016b;5:64.

54. Huang MH, Chen SQ, Wu B, Wu LS, Zhao ZQ. Clinical epidemiological investigation of intestinal pathogenic parasitic infection in children with diarrhea. Chin Public Health. 1999:15:481 (In Chinese). 
55. Cao K, Luo XJ, Wang DL, Zhang Y, Tang D, Chen YS, et al. A preliminary investigation on the infection of human Blastocystis hominis in the children's hospital in Shenzhen. Chin J Clin Lab Sci. 2019;37:222-5 (In Chinese).

56. Liu Y, Qian C, Chen XR, Zeng DQ, He AJ, Yang YH, et al. Investigation of infectious status of Blastocystis hominis in Guangxi. J Appl Prev Med. 2008;14:285-6 (In Chinese)

57. Lu ZC, Hu Y, Liu XQ, Liu DY, Li YW. Analysis intestinal parasitic infection status of 12313 cases of hospital patients in Nanning city. Guangxi J Trop Med. 2015;15:677-80 (In Chinese).

58. Zhang RL, Liang C, Cao AL, He A. Experimental observation on the case of Blastocystis hominis. Guangdong Parasit Soc Ann Rep. 2000;22:59-60 (In Chinese).

59. Zhang SX, Yang CL, Gu WP, Ai L, Serrano E, Yang P, et al. Case-control study of diarrheal disease etiology in individuals over 5 years in southwest China. Gut Pathog. 2016:8:58.

60. Tian LG, Wang TP, Lv S, Wang FF, Guo J, Yin XM, et al. HIV and intestinal parasite co-infections among a Chinese population: an immunological profile. Infect Dis Poverty. 2013;2:18.

61. Wang BB, Yan H, Shi HH, Liu DY, Liao DJ, Liu XQ, et al. Investigating Blastocystis hominis infection of inpatients in two tertiary hospitals of Guangxi. J Guangxi Med Univ. 2016;33:144-6 (In Chinese).

62. Li JH, Cui Q, Wu Y, Liu MC. Investigation of Blastocystis hominis infected by omnivorous insect. Chin J Zoonoses. 2004:728:99 (In Chinese).

63. Yan H. Analyjs of infection status, genotyping and and drugs senitivity of Blastocystis hominis in inpatiets from two tripleastatus hospitals of Guanagxi. Master: Guangxi Medical University; 2015. (In Chinese).
64. Su YP, Li W, He LJ, Yan QY, Shi HF, Zhao KY. Investigation and Research on Blastocystis hominis in Henan Province. Henan Medical Research. 1998;7:157-9 (In Chinese).

65. Yan Y, Su S, Ye J, Lai X, Lai R, Liao H, et al. Blastocystis sp subtype 5 a possibly zoonotic genotype. Parasitol Res. 2007;101:1527-32

66. Jiang T, Wang JZ, Yu YF, Teng XJ, Chu YH, Wu XP, et al. Hospital-based study on the risk factors for Blastocystis hominis infection in the Tengchong City, Yunnan Province. China Chin J Zoonoses. 2019;35:964-9 (In Chinese).

67. Cian A, El Safadi D, Osman M, Moriniere R, Gantois N, Benamrouz-Vanneste $\mathrm{S}$, et al. Molecular epidemiology of Blastocystis sp in various animal groups from two French zoos and evaluation of potential zoonotic risk. PLOS ONE. 2017;12:e0169659.

68. Li WC, Wang K, Gu Y. Occurrence of Blastocystis sp and Pentatrichomonas hominis in sheep and goats in China. Parasit Vectors. 2018;11:93.

69. Zhao GH, Hu XF, Liu TL, Hu RS, Yu ZQ, Yang WB, et al. Molecular characterization of Blastocystis sp in captive wild animals in Qinling Mountains. Parasitol Res. 2017;116:2327-33.

70. Gazzonis AL, Marangi M, Zanzani SA, Villa L, Giangaspero A, Manfredi MT. Molecular epidemiology of Blastocystis sp in dogs housed in Italian rescue shelters. Parasitol Res. 2019;118:3011-7.

71. Greige S, El Safadi D, Khaled S, Gantois N, Baydoun M, Chemaly M, et al. First report on the prevalence and subtype distribution of Blastocystis sp in dairy cattle in Lebanon and assessment of zoonotic transmission. Acta Trop. 2019;194:23-9.
Ready to submit your research? Choose BMC and benefit from:

- fast, convenient online submission

- thorough peer review by experienced researchers in your field

- rapid publication on acceptance

- support for research data, including large and complex data types

- gold Open Access which fosters wider collaboration and increased citations

- maximum visibility for your research: over 100M website views per year

At BMC, research is always in progress.

Learn more biomedcentral.com/submissions 